\title{
Türk Halılarında Kullanılan Kök Boya ve Cehri ile Boyanmış Yün Ipliklerin Haslıklarının lyileştirilmesi
}

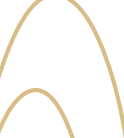 \\ Hüseyin BENLI*}

\section{ÖZET}

Bu çalışmada geleneksel olarak dokunan Türk halı ve düz dokumalarında kullanılan yün ipliklerinin boyanmasında yararlanılan doğal boyarmaddelerden en yaygın olarak kullanılan Kök boya (Rubia tinctoruım L.) ve Cehri (Rhamnus petiolaris Bioss) bitkileri seçilmiştir. Çalışmada geleneksel olarak boyama yöntemlerinden olan önceden mordanlama yöntemi kullanılmıştır. Bakır sülfat ( $\left.\mathrm{CuSO}_{4} \cdot 5 \mathrm{H}_{2} \mathrm{O}\right)$, Demir Sülfat $\left(\mathrm{FeSO}_{4} \cdot 7 \mathrm{H}_{2} \mathrm{O}\right)$, Şap $\left(\mathrm{KAl}\left(\mathrm{SO}_{4}\right)_{2} \cdot 12 \mathrm{H}_{2} \mathrm{O}\right)$, Potasyum dikromat $\left(\mathrm{K}_{2} \mathrm{Cr}_{2} \mathrm{O}_{7}\right)$, Potasyum Kromat $\left(\mathrm{K}_{2} \mathrm{CrO}_{4}\right)$ ve Tartarik asit $\left(\mathrm{C}_{4} \mathrm{H}_{6} \mathrm{O}_{6}\right)$ olmak üzere altı farklı mordan maddesi kullanılmıştır. Mordanlama işleminden sonra boyama işlemleri yapılmıştır. Boyanmış yün iplikleri iki kısma ayılmıştır. İlk kısım boyalı yün ipliklerine herhangi bir son işlem uygulanmamıştır. Doğrudan haslık testleri (Işık ve yıkama haslığı testi) uygulanmıştır. İkinci kısım boyalı yün ipliklerine son işlem yapılmış ve daha sonra benzer haslık testlerine geçilmiştir. Boyalı yün ipliklerin renk verimleri Konika/Minolta 3600d yansıma spektroskopinde Realcolor yazılımı kullanılarak K/S değerleri elde edilmiştir. Kubelka-Munk denklemine göre hesaplanan K/S değeri yorumlanmıştır. CIELab ( $\mathrm{L}, \mathrm{a}, \mathrm{b})$ koordinatları tespit edilmiştir. Sonuçlar karşılaştırılmış ve art işlemler sonunda haslık değerleri 1-2 puan artış göstermiştir.

Anahtar kelimeler: Türk halısı, Doğal boyama, Kök boya, Cehri, Mordan, Haslık özellikleri

Öğr. Gör., Erciyes Üniversitesi Mustafa Çıkrıçıı̆lu M.Y.O., Kimya Teknolojisi, Kayseri/ Turkey, e-posta: hbenli@erciyes. edu.tr.

\section{ABSTRACT}

This study explores natural dyes madder (Rubia tinctoruim L.) and dyer's rocket (Rhamnus petiolan's Bioss) plats which are widely used for dyeing wool yarn of the traditional Turkish carpets and flat weavings. Traditional methods to study the pre-mordant dyeing method is used. Six different mordant elements are used such as Copper sulphate $\left(\mathrm{CuSO}_{4} \cdot 5 \mathrm{H}_{2} \mathrm{O}\right)$, Iron Sulphate $\left(\mathrm{FeSO}_{4} \cdot 7 \mathrm{H}_{2} \mathrm{O}\right)$, Alum $\left(\mathrm{KAl}\left(\mathrm{SO}_{4}\right)_{2} \cdot 12 \mathrm{H}_{2} \mathrm{O}\right)$, Potassium dichromate $\left(\mathrm{K}_{2} \mathrm{Cr}_{2} \mathrm{O}_{7}\right)$, Potassium chromate $\left(\mathrm{K}_{2} \mathrm{CrO}_{4}\right)$ and Tartaric acid $\left(\mathrm{C}_{4} \mathrm{H}_{6} \mathrm{O}_{6}\right)$. Then, mordant dyeing is made. Dyed wool yarn is divided into two parts. The first part of any final action did not apply to dyed wool yarn. Direct fastness testing (light and wash fastness test) was performed. Last treatment was applied to the second part of the dyed wool yarn and then similar fastness tests were made. Colour yield of dyed wool yarn Konika / Minolta 3600d software using reflectance spectroscopy Realcolor at the K/S values were obtained. Kubelka-Munk equation calculated according to $\mathrm{K} / \mathrm{S}$ value is interpreted. CIELab $(\mathrm{L}, \mathrm{a}, \mathrm{b})$ coordinates were determined. Results are compared and the value of transactions at the end of the 1-2 score is increased.

Keywords: Turkish Carpet, Natural Dyeing, Madder Red, Buckthorn, Mordant, Fastness properties.

\section{Giriş}

Türkler yaşadı ̌̆ı Orta Asya'da halı, keçe ve düz dokuma yaygıları (Kilim, Cicim, Zili, Sumak) yaygı ve örtü malzemesi olarak kullanmışlardır. Yaylacılık yapan 
Türklerin kolayca taşıyabildikleri bu malzeme aynı zamanda kişinin refah seviyesini de göstermektedir. Halı varlığın simgesi olarak bilinmektedir. Türklerin halı ve kilimde kullandıkları dokuma maddeleri olarak yün, tiftik, deve yünü ve pamuktur. Bunlar içinde en çok kullanılan yün lifleridir ${ }^{1}$.

Türk halı ve kilimlerini önemli kılan özellikleri dokumasının sıklığı, renklerinin sabitliği ve desenlerinin özgün olmasıdır. Renklendirmede doğal boyalar kullanmışlardır. Bu doğal boyalar bitkilerden, meyvelerden ve hayvanlardan elde edilmiştir. Renk ve boya hazırlamak ve halı ipini dokumaya hazırlamak Türklerde anneden kıza geçen bir gelenek olmuştur. Orta Asya Türk boylarının boyama hazırlık yöntemleri de birbirlerini çok benzemektedir. Boyarmadde kaynakları olarak da çoğunlukla Orta Asya bozkırlarındaki bitkiler olmuştur ${ }^{2}$.

Tarihsel kanıtlar antik dönemde bazı bölgelerin bazı tekstil materyallerini boyadıklarını göstermektedir. İpek Çin'de, pamuk Hindistan'da yün ise Mezopotamya'da boyanmıştır. Renkli ipliklerin ilk görüldükleri bölge ise M.Ö. 6. y.y.'da Türkiye'deki Çatal Höyük bölgesidir³.

Türkler Anadolu'ya yerleşmeleriyle birlikte gelenek ve kültürlerini dokudukları halı, kilim gibi yaygılara yansıtmışlardır. Bunu yaparken kullanmış oldukları boyalı yün ipliklerinde hem yöresel bitkileri boya hammaddesi olarak hem de kendine özgü boyama yöntemleri geliştirip uygulamışlardır.

M.Ö. 7.y.y.'daki tabletlerde Mordanlı, Küp boyama yöntemlerinden bahsedilmektedir. Mavi için İndigo, kırmızı için Kök boya, sarı için Zerdeçal, yeşil renk için ise sarı ve indigo'nun kullanılmış olduğundan bahsedilmektedir. Dünya'nın en eski halısı olarak kabul edilen ve M.Ö. 5004 yıllarına tarihlendirilen Pazırık halısında kırmızı renk olarak kök boya'nın kullanılmış olduğu tespit edilmiştir ${ }^{5}$.

Doğal boyalar 19. y.y.'ın sonlarına kadar Anadolu'da ve Dünya'da oldukça yaygın bir şekilde kullanılmıştır ${ }^{6}$. Özellikle Türk Kırmızısı veya Edirne Kırmızısı olarak bilinen Kök boya (Alizarin) Dünya boya literatürüne girmiştir. Cehri, safran gibi diğer boyalarda oldukça fazla bilinen doğal boyarmadde kaynaklarıdır?.

B. Deniz, "Türk Dünyasında Halı ve Düz Dokuma Yaygıları”, AKM Yayını. Ankara, 2000

2 G. Durduyeva, "Türkmen Halılarında Boyaların Yeri", Türk Soylu Halkların Halı, Kilim ve Cicim Sanatı Uluslararası Bilgi Şöleni, Kayseri, 1996, s. 111

3 R. Chenciner, "Madder Red. A History of Luxury and Trade", p: 30, London and New york, 2003.

4 O. Aslanapa, Türk Halı Sanatınin Bin Yill, Eren yay. S:9, 1987

5 R. Karadağ, Doğal Boyamacilı, T.C. Kültür ve Turizm Bakanlığı. Ankara, 2007.

6 T. Baykara, "Kök boya", Arış, s: 64,1,4,1998.

7 ì. Öztürk, Doğal Bitkisel Boyalarla Yün Boyama, Dokuz Eylül Yayınları, İzmir, 1999.
Bitkisel materyallerde bulunan fenolik bileşikler, fenolik asit ve flavonoidler ${ }^{8}$ olarak bulunmaktadırlar. Kimyasal olarak bakıldığında bu yapılar aromatik halkalı bileşikler olup renkli yapıları meydana getirmektedirler. Şekil 1,2 ve 39,10.

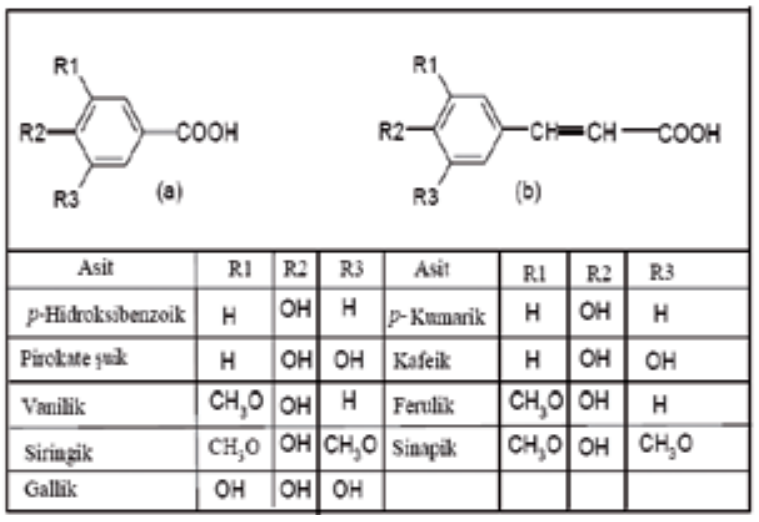

Şekil 1. Fenolik aitlerin genel yapısı: a) Benzoik asit türevleri b) Sinamik asit türevleri

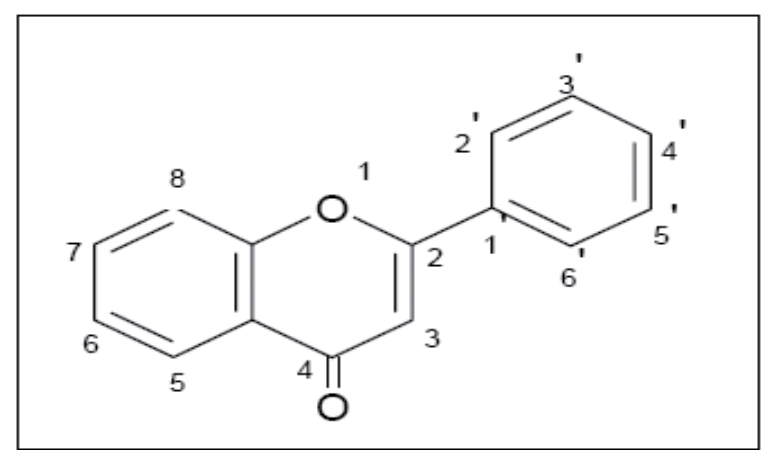

Şekil 2. Flavonoidlerin genel yapısı

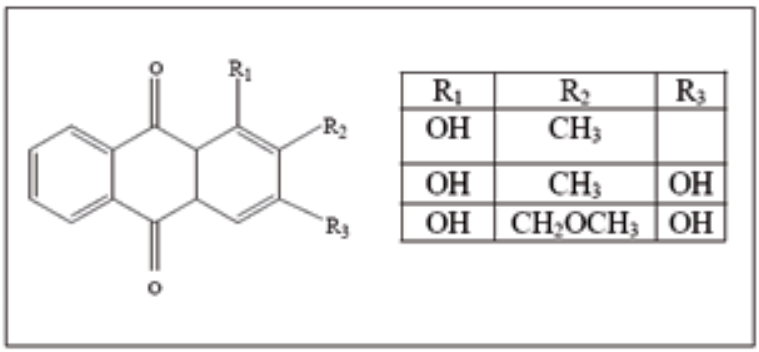

Şekil 3. Antrakinon

Bu çalışmanın amacı yüzyıllardır süre gelen geleneksel Türk el dokumalarında kullanılan yün ipliklerinin boyanmasında kullanılan doğal boyarmaddelerin en bilinen ve yaygın olanlarından kök boya ve Cehri bitkileri ile boyanmış yün ipliklerinin haslıklarının (özellikle ışık) artırılmasıdır.

8 N. T. Manojlovic, "Antifungal activity of Rubia tinctorum, Rhamnuz frangula nad Caloplaca cerina" Fitoterapia, 76, (2005), 244246.

9 A. C. Dweck, "Natural Ingredients for colouring and styling", T Klin J. Cosmetol 2003. UK.

10 N. M. Nizamlığlu, S. Nas, "Meyve ve Sebzelerde Bulunan Fenolik Bileşikler; Yapıları ve Önemleri”, 2010, 5(1), s. 20-35. 


\subsection{Kök boya'nın kimyasal yapısı}

Kök boya yapısında birden fazla boyarmadde ihtiva eder. Bunlar; Rubiritrik asit, Alizarin, Rubiadin glikoziti, Rubiadin, Purpurin, Ksanton purpurin, Pseudo purpurin, Munjistin $\operatorname{dir}^{11,12}$. Şekil 4.a. ve b.

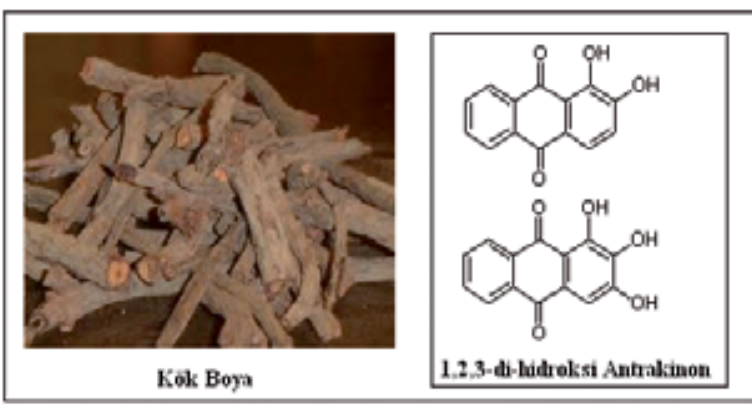

Şekil 4.a. Kök boya

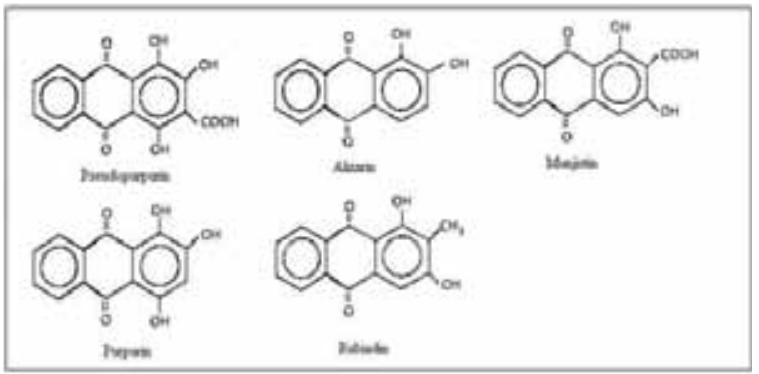

Şekil 4.b. Kök boyada bulanan kimyasal yapılar

\subsection{Cehri'nin kimyasal yapısı}

Kimyasal açıdan Rhamnatinin bir glikoziti olan ksanto Rhamnetin ve bunun yanında Rhamnazin ve Quercetin boyarmaddelerini glikozit halinde ihtiva eder ${ }^{13,14}$. Şekil 5 .a ve b.

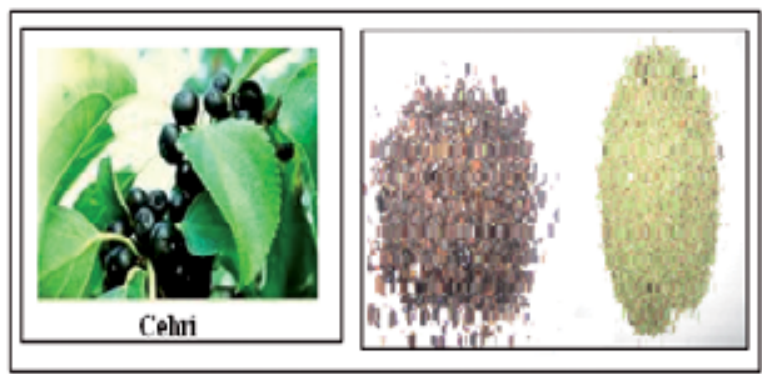

Şekil 5.a: Cehri

11 Bosakova et.al., Determination of Licidin in Rubia Tinctorum Anglycones by an HPLC Method with Isocratic Elution, J. High Resol. Chromatogr, 2000, 23, (10) 600-602.

12 Angelini, L., G., et.al. "Rubia tinctorum a source of natural dyes: agronomic evaluation,quantitative analysis of alizarin and industrial assays", Industrial crops and products 6 (1997) s.303311 .

13 Goverdina,C. D. Derksen., et.al., "Two Validated HPLC Methods for the Quantification of Alizarin and other Antraquiones in Rubia Tinctorum Cultivars". Phytochemical Analysis, 406, 2004.

14 Anonim, Bitkilerden Elde Edilen Boyalarla Yün Liflerinin Boyanması. Sanayi ve tic. Bakanlı̆̆ı, Ankara, 1991.

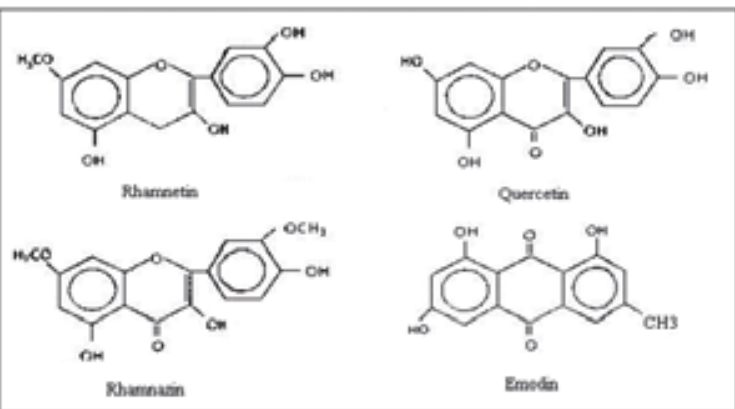

Şekil 5.b. Cehri'de bulunan kimyasal yapılar

\section{Materyal ve Metod}

\subsection{Materyal}

Bu çalışmada kullanılan materyal daha önce ön terbiye işlemi görmemiş \%100 yün ipliklerdir. Doğal boyarmadde kaynağı olarak öğütülmüş ve toz halindeki Kök boya C.I. Natural Red $8^{15}$ ve Cehri C.I. Natural Yellow $2^{16}$ kullanılmıştır. Kullanılan Mordan maddeleri ve art işlem kimyasalları analitik saflıktadır.

\subsection{Mordanlama metodu}

Mordan kelimesi Latince bir kelime olan "Mordere" "den gelmektedir. "Isırmak" anlamına gelir ve üzerine tutturmak anlamında kullanılmıştır ${ }^{17}$. Bilinen üç fark1 mordanlama yöntemi vardır. Bunlar önceden Mordanlama, birlikte mordanlama ve sonradan mordanlama metotlarıdır ${ }^{18}$. Bu çalışmada önceden mordanlama yöntemi kullanılarak yün iplikler boyamaya hazır hale getirilmiştir. Bakır sülfat $\left(\mathrm{CuSO}_{4} \cdot 5 \mathrm{H}_{2} \mathrm{O}\right)$, Demir Sülfat $\left(\mathrm{FeSO}_{4} \cdot 7 \mathrm{H}_{2} \mathrm{O}\right)$, Şap $\left(\mathrm{KAl}\left(\mathrm{SO}_{4}\right)_{2} \cdot 12 \mathrm{H}_{2} \mathrm{O}\right)$, Potasyum dikromat $\left(\mathrm{K}_{2} \mathrm{Cr}_{2} \mathrm{O}_{7}\right)$, Potasyum Kromat $\left(\mathrm{K}_{2} \mathrm{CrO}_{4}\right)$ ve Tartarik asit $\left(\mathrm{C}_{4} \mathrm{H}_{6} \mathrm{O}_{6}\right)$ olmak üzere altı farklı mordan maddesi kullanılmıştır. Miktarlar materyal ağırlığı üzerinden hesaplanmıştır. Yün iplikleri Şekil 6'de gösterilen prosese göre ayrı ayrı mordanlanmıştır. $25^{\circ} \mathrm{C}$ 'de 1 sıtma işlemi başlatılarak yaklaşık olarak 1 saatte kaynama sıcaklığına çıkılmıştır ve burada 1 st çalışılmıştır. Mordanlama reçeteleri Tablo l'de gösterilmektedir.

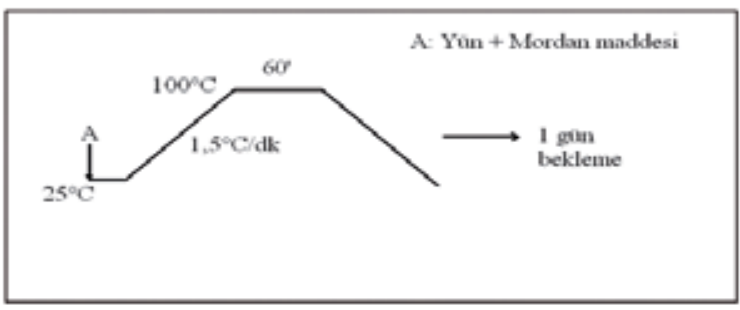

Şekil 6. Yün ipliğinin mordanlama prosesi

15 T. Bechtold, et.al. Natural dyes in modern textile dyehouses Journal of cleaner production 11 (2003) s. 499-509.

16 Colour Index, The Society of Dyers and Colourists. 2.ed. 1956 ,

17 J. Dean, The Craft of Natural Dyeing. England, 2003

18 B., C. N. Ranjana, Saikia, Isolation of colour components from native dye-bearing plants in northeastern India. Bioresource Tech. 96 (2005), 363-372; Önal. A., Extraction of Dyestuff from Onion and its application in the dyeing of wool, feathere-leather and cotton, J. Chemistry, 1995 
Tablo 1. Mordanlama ve boyamada kullanılan Mordan maddeleri ve boyarmadde miktarları.

\begin{tabular}{|c|c|c|c|}
\hline & Mordan ă̆.(\%) & Yün İplik ağ. (gr) & Boyarmadde ağ.(gr) \\
\hline $\mathrm{CuSO}_{4} \cdot 5 \mathrm{H}_{2} \mathrm{O}$ & 2,5 & 2,5 & 2,5 \\
\hline $\mathrm{FeSO}_{4} \cdot 7 \mathrm{H}_{2} \mathrm{O}$ & 2,5 & 2,5 & 2,5 \\
\hline $\mathrm{KAl}\left(\mathrm{SO}_{4}\right)_{2} \cdot 12 \mathrm{H}_{2} \mathrm{O}$ & 30 & 2,5 & 2,5 \\
\hline $\mathrm{K}_{2} \mathrm{Cr}_{2} \mathrm{O}_{7}$ & 2,5 & 2,5 & 2,5 \\
\hline $\mathrm{K}_{2} \mathrm{CrO}_{4}$ & 2,5 & 2,5 & 2,5 \\
\hline $\mathrm{C}_{4} \mathrm{H}_{6} \mathrm{O}_{6}$ & 2,5 & 2,5 & 2,5 \\
\hline
\end{tabular}

\subsection{Boyama metodu}

Mordanlama işleminden sonra en az bir gün bekletilen yün iplikleri Şekil 7'de gösterilen boyama prosesine göre boyanmıştır. Boyama işleminde geleneksek olarak bilinen çektirme metodu kullanılmıştır. Bütün mordanlama ve boyama işlemleri HT Roaches Model-MB marka laboratuar tipi boyama makinesinde, $200 \mathrm{ml}$ 'lik paslanmaz çelik tüplerde ve gliserin banyosunda yapılmıştır. Boyamaya oda sıcaklığında başlayarak $1,5-2^{\circ} \mathrm{C} / \mathrm{dk}$ ısıtma hızıyla $100^{\circ} \mathrm{C}$ 'ye yükseltilmiş ve bu sıcaklıkta $60 \mathrm{dk}$. çalışılmış ve soğutulmuş, daha sonra boyalı yün ipliklere sabunlu yıkama ve durulama işlemleri yapılmıştır.

Mordanlama işlemleri ile yüne bağlanmış olan metal iyonları $\left(\mathrm{Me}^{+}\right)$sayesinde bitkilerde bulunan Fenolik asit ve Flovanoid türevleri gibi kimyasal yapılar (Şekil 4 ve 5) yüne bağlanmaktadır. Yün, Mordan ve boyarmadde arasındaki kimyasal mekanizma Şekil 8'de gösterilmektedir ${ }^{19}$. Boyanan yün iplikler kurutulduktan sonra 2'ye ayrılmışlardır. Birinci kısma herhangi bir işlem yapılmadan haslık testlerine geçilmiştir.

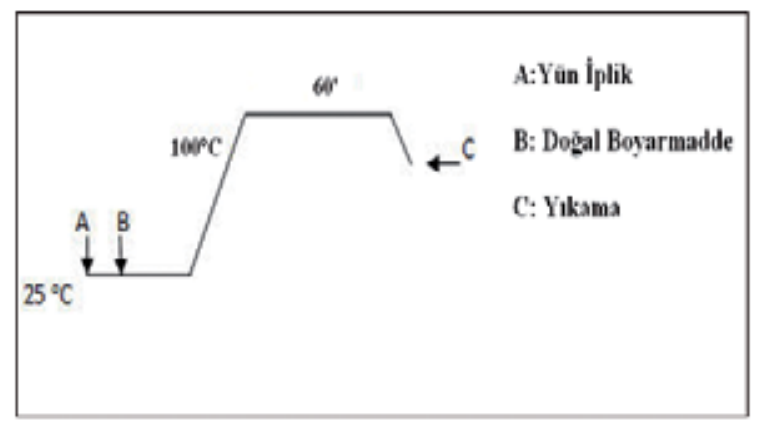

Şekil 7. Boyama prosesi

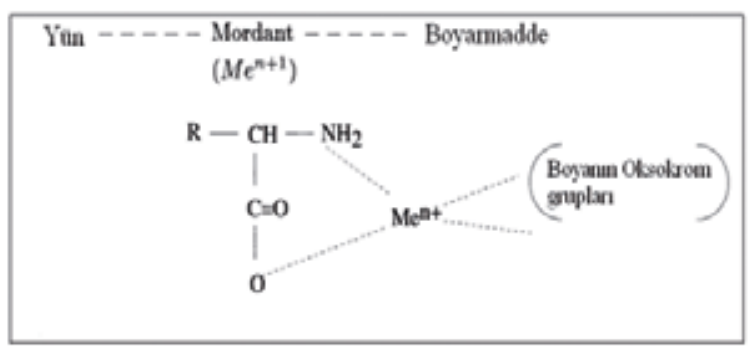

Şekil 8. Yün-Mordan-Boyarmadde arasındaki kimyasal bağ ilişkisi

\subsection{Art (son) işlemler}

$\mathrm{Bu}$ çalışmada boyanan yünlü ipliklerin ikinci yarısına haslık değerlerini artırmak için art (son) işlem uygulanmıştır. Bunun için \%3 Amonyum oksalat $\left(\left(\mathrm{NH}_{4}\right)_{2} \mathrm{C}_{2} \mathrm{O}_{4} \cdot \mathrm{H}_{2} \mathrm{O}\right)$, \%3 Üre $\left(\mathrm{H}_{2} \mathrm{~N}-\mathrm{CO}-\mathrm{NH}_{2}\right)$ ve \%3 Amonyak $\left(\mathrm{NH}_{3}\right)$ çözeltisi hazırlanmıştır. Hazırlanan bu çözeltiye boyalı yünlü iplikler ilave edilerek çözelti kaynama noktasına çıkartılmış ve burada 10 dakika çalıştıktan sonra çözelti soğumaya bırakılarak bir gün bekletilmiş, kurutulmuştur ve birinci kısma yapılan testler uygulanmıştır.

\subsection{Haslık özelliklerinin ölçülmesi}

Yıkama haslığ ${ }^{20}$ testi $40^{\circ} \mathrm{C}^{\prime}$ de $0,5 \mathrm{~g} / \mathrm{lt}$ yıkama maddesi ile (ECE marka) 30 dk Gyrowash standart yıkama makinesinde muamele edilmiştir. Flotte oranı 1:50 dir. Daha sonra durulanmış ve $60^{\circ} \mathrm{C}^{\prime}$ de kurutulmuştur. Lekeleme ve renk değişimleri Gri-skala ile değerlendirilmiştir. (Skala 1 ile 5 arasındadır. 1 çok kötü 5 ise mükemmeldir.) Işık hasl $ı \breve{g ̆}^{21}$ değerleri xenon arc lambası ile suni ışık kullanılarak

20 TS EN 20105-C03, Tekstil-Renk Haslı̆̆ı Deneyleri-Bölün CO3: Yıkamaya Karşı Renk Haslığı Tayini-Deney 3, Türk Standartları, Nisan 1999.

21 TS 1008 EN ISO 105-B02, Yapay ışığa karşı Renk Haslığı Tayini, Türk Standartları, Ksenon ark soldurma lambası deneyi.

19 A. Önal, Extraction of Dyestuff from Madder Plant and Dyeing of Wool, Feathered-leather and cotton, J. Chemistry, 1995. 


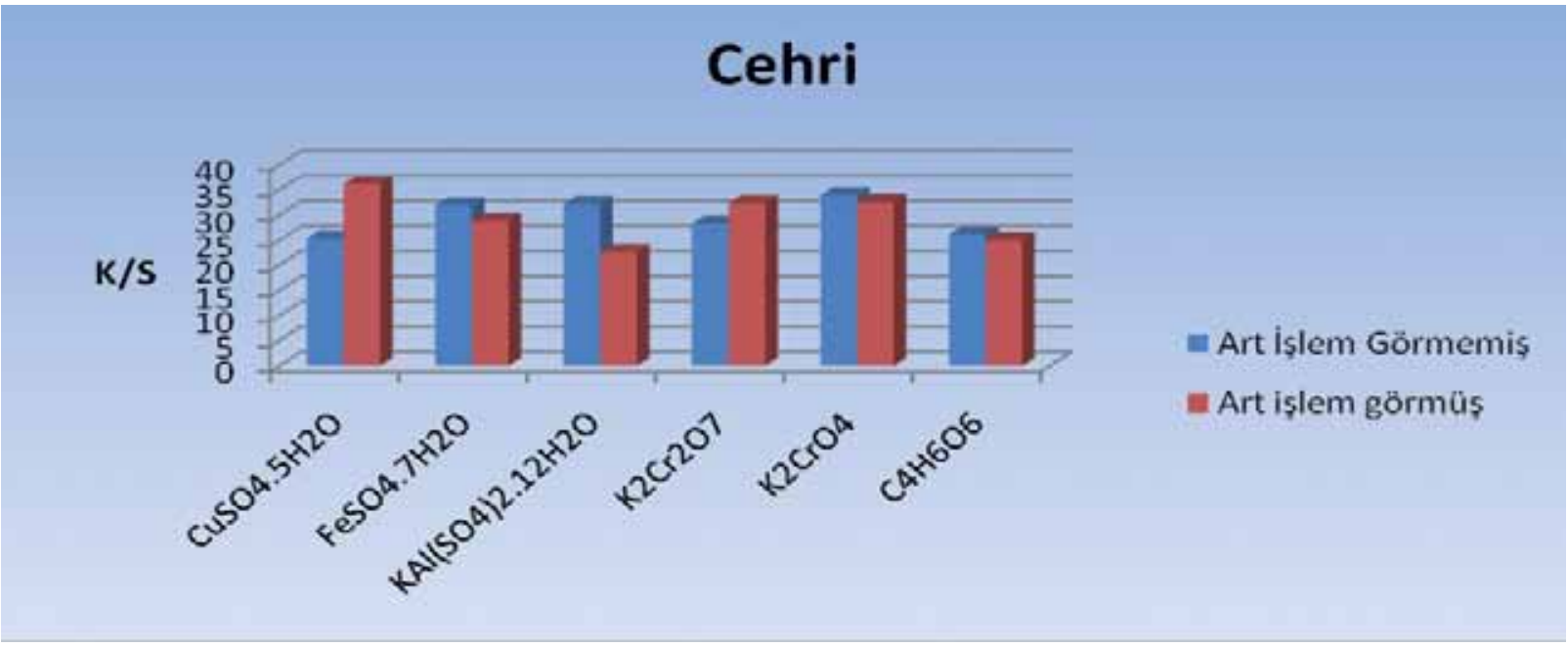

Şekil 9. Cehri ile boyanmış yün ipliklerin art işlem görmüş ve görmemiş numunelerin K/S değerlerinin karşılaştırılması

\section{Kök Boya}

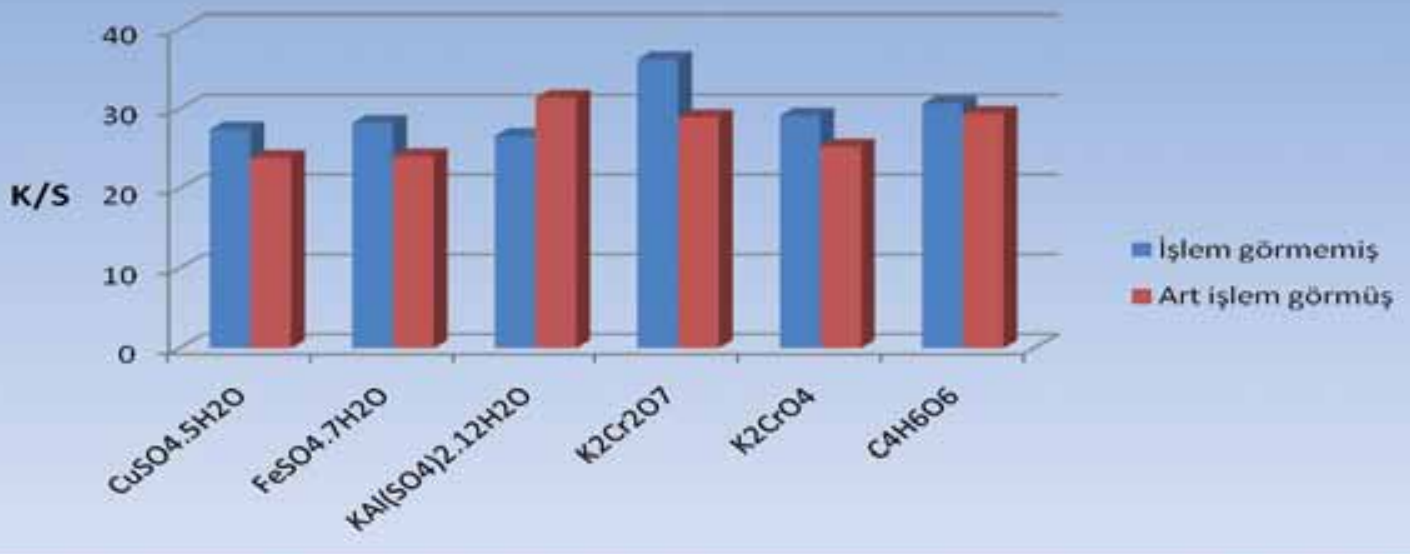

Şekil 10. Kök boya ile boyanmış yün ipliklerin art işlem görmüş ve görmemiş numunelerin K/S değerlerinin karşılaştııılması

\section{Kök boya}

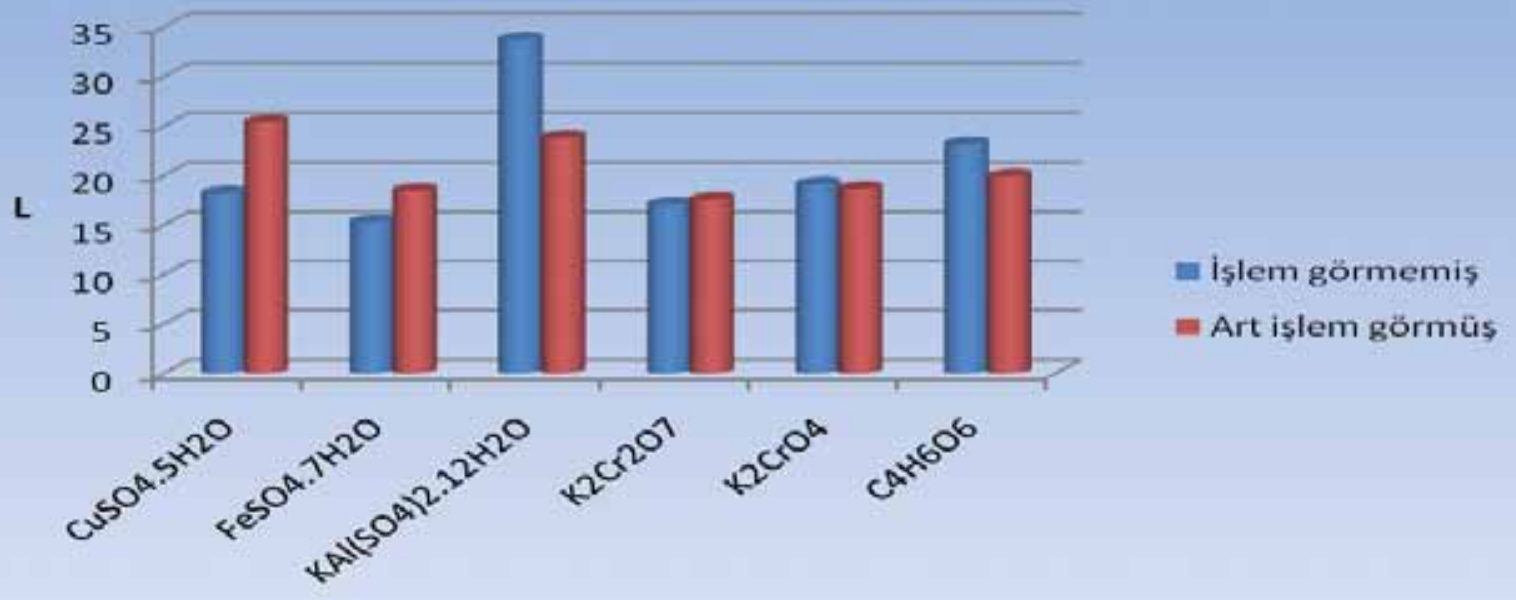




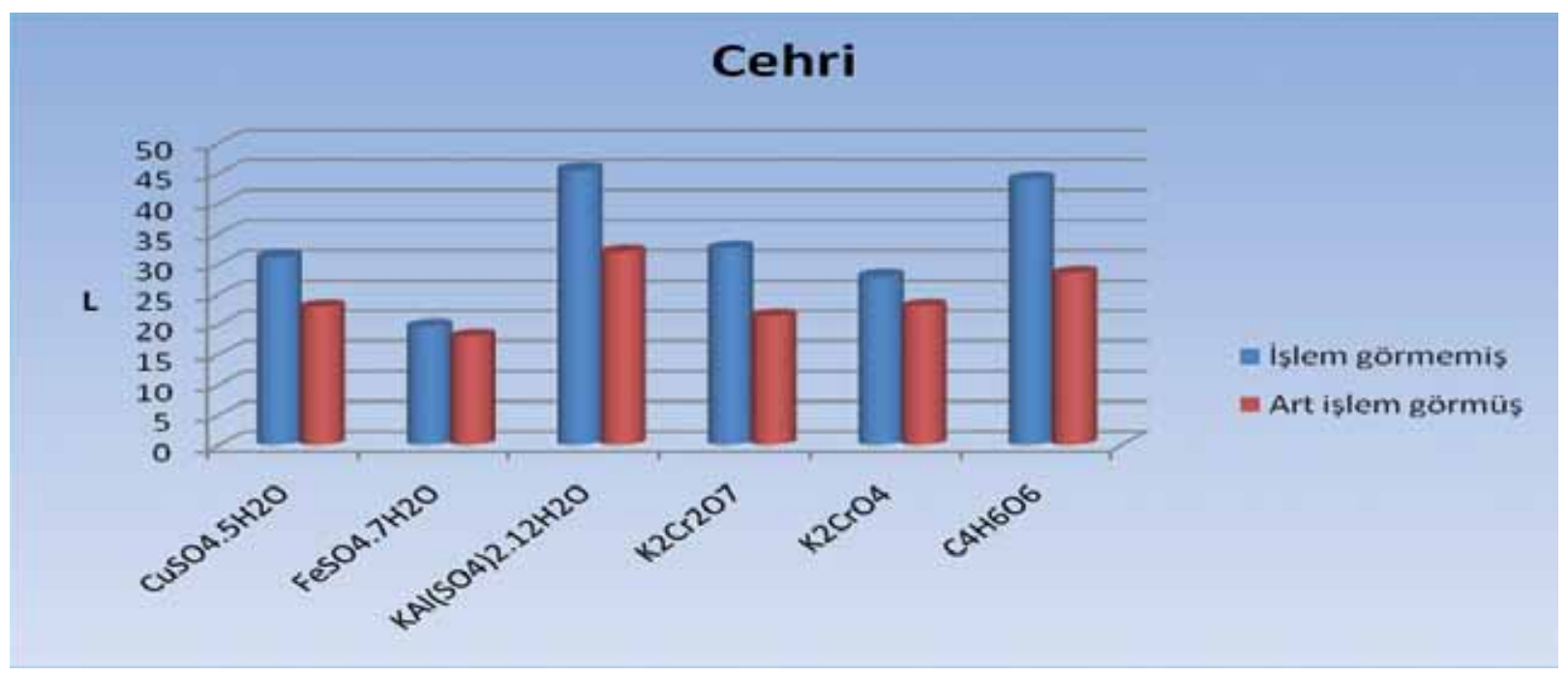

Şekil 12. Cehri ile boyanmış yün ipliklerin art işlem görmüş ve görmemiş numunelerin "L" değerlerinin karşılaştırılması

yapılmıştır22,23. (Skala 1 ile 8 arasındadır. 1 çok kötü 8 ise mükemmeldir.)

\subsection{Hunter koordinatları}

Boyalı yün ipliklerin renk verimleri Konika/Minolta 3600d yansıma spektroskopinde Realcolor yazılımı kullanılarak K/S değerleri elde edilmiştir. KubelkaMunk denklemine göre hesaplanan K/S değeri yorumlanmıştır. Boyanmış yün ipliklerin art (son) işlem görmüş ve görmemiş olanları ayrı ayrı Hunter koordinatları CIELAB L, a ve b değerleri x, y, z aşağıdaki denklemler kullanılarak hesaplanmıştır ${ }^{24}$.

$$
\begin{aligned}
& \mathrm{L}=10 \mathrm{y}^{1 / 2} \\
& \mathrm{a}=17,5(1,02 \mathrm{x}-\mathrm{y}) / \mathrm{y}^{1 / 2} \\
& \mathrm{~b}=7(\mathrm{y}-0,84 \mathrm{z}) / \mathrm{y}^{1 / 2}
\end{aligned}
$$

Doğal boyarmaddeler ile boyanmış yün ipliklerinin renk verimleri Kubelka-Munk denklemine göre değerlendirilmiştir. Renkli yüzeylerin boyama veriminin belirlenmesinde kullanılan en önemli kanun Kubelka-Munk denklemine göre hesaplanan K/S değeridir. Aşağıdaki denklem ile hesaplanır ${ }^{25}$.

$$
F(R)=\frac{(1-R)^{2}}{2 R}
$$

R: Reflektans

K: Absorpsiyon Katsayısı

S: Saçılma Katsayısı

C: Absorbsiyon bölgesinin konsantrasyonu

A: Absorbans

22 TS 423-3-EN 20105 A03, Tekstil-Renk Haslığı Tayin Metotlarl-Bölüm A03: Renk Akmasının Değerlendirilmesinde Gri skalanın Kullanılması.

23 TS 423-3-EN 20105 A03, Tekstil-Renk Haslığı Tayin Metotları-Bölüm A03: Renk Akmasının Değerlendirilmesinde Gri skalanın Kullanılması,

24 W. Ingamells, Colour for Textiles a User's Handbook. SDC,UK. 1993.

25 K. Duran, Tekstilde Renk Ölçümü ve Reçete Çıkarma. E. Ü. Yayın no: 17. İzmir, 2001

\section{Bulgular}

Altı farklı mordan maddesi kullanılarak iki farklı doğal boyarmadde kaynağından yararlanılarak boyama işlemleri yapılmıştır. Boyanan yün iplikleri daha sonra iki ayrı gruba ayrılmıştır. Birinci grup boyalı yün ipliklerine her hangi bir art işlem yapılmadan normal ışık ve yıkama haslıklar yapılmıştır. İkinci grup boyalı yün ipliklere ise haslık değerlerinin artışını sağlamak için art (son) işlem uygulanmıştır. Art işlem sonrasında bunlara da aynı haslık testleri uygulanmıştır. Elde edilen sonuçlar Tablo 2 ve 3'de gösterilmektedir. K/S değerleri de Tablo 4, Şekil 9 ve 10'da görülmektedir. CIE L a b değerleri de Tablo 5'de toplu olarak görülmektedir.

Tablo 4'de Kök boya ile boyanmış yün ipliklerinin K/S değeri Bakır sülfat, Demir sülfat, Dikromat, Kromat ve Tartarat için düşerken şap için bu değerin yükseldiği görülmektedir.

Cehri ile boyanmış yün ipliklerinin K/S değerleri ise Demir sülfat, şap da düşerken, Bakır sülfat ve dikromat ile yapılan çalışmada artış olduğu ve diğerlerinde ise dikkate değer bir değişim olmadığı görülmektedir. Kök boya ve Cehri ile boyanmış yün ipliklerin art işlem görmüş ve görmemiş numunelerin " $\mathrm{L}$ " değerlerinin karşılaştırılması Şekil 11 ve 12'de görülmektedir.

\section{Sonuç}

Bütün yıkama haslıklarında hem kök boya ile boyanış hem de cehri ile boyanmış olan yün ipliklerinin haslık değerlerinde art işlem ile birlikte yarım ile bir puan arasında bir artışın olduğu görülmektedir.

Işık haslıkları yapılan art işlemlerden sonra yarım ile bir puanlık bir artışın olduğu görülmektedir.

K/S değerine göre Cehri ile boyanmış yün ipliklerinin Bakır sülfat ve Potasyum dikromat ile Kök boya ile boyanmış yün ipliklerinin de şap ile mordanlanması sonrasında yapılan art işlemleri ile boyama veriminin 
Tablo 2: Art işlem görmemiş boyalı yün ipliklerin haslık değerleri tablosu

\begin{tabular}{|c|c|c|c|c|c|c|}
\hline \multirow{4}{*}{$\begin{array}{l}\text { Mordan maddeleri } \\
\mathrm{CuSO}_{4} \cdot 5 \mathrm{H}_{2} \mathrm{O}\end{array}$} & \multicolumn{3}{|c|}{ Kök Boya } & \multicolumn{3}{|c|}{ Cehri } \\
\hline & \multicolumn{2}{|c|}{ Yıkama Haslığı } & \multirow{3}{*}{$\begin{array}{c}\text { Işık Haslığı } \\
3\end{array}$} & \multicolumn{2}{|c|}{ Yıkama Haslığı } & \multirow{3}{*}{$\frac{\text { Işık Haslığ }_{1}}{3}$} \\
\hline & L & & & & & \\
\hline & 4 & 4 & & 4 & 4 & \\
\hline $\mathrm{FeSO}_{4} \cdot 7 \mathrm{H}_{2} \mathrm{O}$ & 4 & 4 & 4 & 3 & 4 & 5 \\
\hline $\mathrm{KAl}\left(\mathrm{SO}_{4}\right)_{2} \cdot 12 \mathrm{H}_{2} \mathrm{O}$ & 4 & 4 & 4 & 3 & 4 & 4 \\
\hline $\mathrm{K}_{2} \mathrm{Cr}_{2} \mathrm{O}_{7}$ & 4 & 5 & $4 / 5$ & 4 & 4 & $4 / 5$ \\
\hline $\mathrm{K}_{2} \mathrm{CrO}_{4}$ & 4 & 4 & 4 & 4 & 4 & 4 \\
\hline $\mathrm{C}_{4} \mathrm{H}_{6} \mathrm{O}_{6}$ & 3 & 4 & 4 & 3 & 4 & 4 \\
\hline
\end{tabular}

L*: Lekeleme, R*: Renk Değişimi

Tablo 3: Art işlem görmüş boyalı yün ipliklerin haslık değerleri tablosu

\begin{tabular}{|c|c|c|c|c|c|c|}
\hline \multirow{4}{*}{$\begin{array}{l}\text { Mordan maddeleri } \\
\mathrm{CuSO}_{4} \cdot 5 \mathrm{H}_{2} \mathrm{O}\end{array}$} & \multicolumn{3}{|c|}{ Kök Boya } & \multicolumn{3}{|c|}{ Cehri } \\
\hline & \multicolumn{2}{|c|}{ Yıkama Haslığı } & \multirow{3}{*}{$\begin{array}{c}\text { Işık Haslığı } \\
4 / 5\end{array}$} & \multicolumn{2}{|c|}{ Yıkama Haslığı } & \multirow{2}{*}{ Işık Haslığı } \\
\hline & $\mathrm{L}$ & & & L & & \\
\hline & $3 / 4$ & 4 & & $3 / 4$ & 4 & 5 \\
\hline $\mathrm{FeSO}_{4} \cdot 7 \mathrm{H}_{2} \mathrm{O}$ & 4 & 4 & 5 & 4 & 4 & 5 \\
\hline $\mathrm{KAl}\left(\mathrm{SO}_{4}\right)_{2} \cdot 12 \mathrm{H}_{2} \mathrm{O}$ & 4 & 4 & 5 & 4 & 4 & 5 \\
\hline $\mathrm{K}_{2} \mathrm{Cr}_{2} \mathrm{O}_{7}$ & 4 & 4 & 5 & 4 & 5 & $5 / 6$ \\
\hline $\mathrm{K}_{2} \mathrm{CrO}_{4}$ & 4 & 4 & 5 & 4 & 4 & 5 \\
\hline $\mathrm{C}_{4} \mathrm{H}_{6} \mathrm{O}_{6}$ & $4 / 5$ & 5 & $4 / 5$ & 3 & 4 & $4 / 5$ \\
\hline
\end{tabular}

artmış olduğu görülmüştür. Bu artış gösteren mordan maddeleri ve art işlemler önerilmektedir. "L" değerlerinin; Bakır sülfat, demir sülfat ve potasyum dikromat ile mordanlanan kök boyalı yünlerde art işlem sonunda artış olduğu, şap, kromat ve tartarik asit ile mordanlanmış olan yünlü ipliklerde ise azaldı ̆̆ı görülmektedir. Cehri ile boyanmış yünlü ipliklerde ise şap, dikromat, kromat ve tartarik asit ile mordanlanmış yünlü ipliklerde "L"değerinin arttığı, bakır ile demir sülfat ile mordanlanmış ipliklerde ise azaldığı görülmüştür.

\section{Kaynaklar}

Aslanapa Oktay (1987), Türk Halı Sanatı'nın Bin Yilı, Eren Yayınları, İstanbul.

Angelini, Luciana vd. (1997), "Rubia Tinctorum a Source of Natural Dyes: Agronomic Evaluation, Quantitative Analysis of Alizarin and Industrial assays". Industrial Crops and Proucts, 6, s. 303-311.
Baykara Tuncer (1998), "Kökboya”, Arış, 1, 4, s. 64-71.

Bechtold, Thomas vd. (2003), "Natural dyes in modern textile dyehouses", Journal of Cleaner Production, 11, s. 499-509.

Bosakova, Zuzana and Jan, Persl (2000), “Determination of Licidin in Rubia Tinctorum Anglycones by an HPLC Method with Isocratic Elution", J. High Resol, Chromatogr, 23, (10) 600-602.

Chenciner, Robert (2003), "Madder Red. A History of Luxury and Trade", p. 30, London and Newyork.

Colour Index (1956), The Society of Dyers and Colourists, 2.ed.

Dean, Jenny (2003), The Craft of Natural Dyeing, England,

Deniz, Bekir (2000), Türk Dünyasinda Halı ve Düz Dokuma Yaygiları, Ankara: AKM Yayını.

Duran, Kerim (2001), Tekstilde Renk Ölçümü ve Reçete Çıkarma, E.Ü. Yayın no: 17, İzmir.

Durduyeva, Gülsultan (1996), "Türkmen Halılarında Boyaların Yeri", Türk Soylu Halkların Halı, Kilim ve Cicim Sanatı Uluslararası Bilgi Şöleni, Kayseri. 
Tablo 4: Art işlem görmüş ve görmemiş boyalı yün ipliklerin K/S değerleri tablosu

\begin{tabular}{|l|c|c|c|c|}
\hline \multirow{2}{*}{$\begin{array}{c}\text { Mordan } \\
\text { maddeleri }\end{array}$} & Kök Boya & Cehri Işlem görmemiş & Art İşlem Görmüş \\
\cline { 2 - 5 } & 27,36 & 25,33 & 23,73 & Kök Boya \\
\hline $\mathrm{CuSO}_{4} \cdot 5 \mathrm{H}_{2} \mathrm{O}$ & 28,19 & 31,90 & 23,94 & 28,84 \\
\hline $\mathrm{FeSO}_{4} \cdot 7 \mathrm{H}_{2} \mathrm{O}$ & 26,51 & 32,12 & 31,38 & 22,59 \\
\hline $\mathrm{KAl}_{\left(\mathrm{SO}_{4}\right)_{2} \cdot 12 \mathrm{H}_{2} \mathrm{O}}$ & 36,13 & 28,30 & 28,89 & 32,29 \\
\hline $\mathrm{K}_{2} \mathrm{Cr}_{2} \mathrm{O}_{7}$ & 29,09 & 33,91 & 25,16 & 32,59 \\
\hline $\mathrm{K}_{2} \mathrm{CrO}_{4}$ & 30,64 & 26,13 & 29,33 & 25,08 \\
\hline $\mathrm{C}_{4} \mathrm{H}_{6} \mathrm{O}_{6}$ & & & & 29 \\
\hline
\end{tabular}

Tablo 5: Art işlem görmüş ve görmemiş boyalı yün ipliklerin CIELab değerleri tablosu

\begin{tabular}{|c|c|c|c|c|c|c|c|c|c|c|c|c|}
\hline \multirow{3}{*}{$\begin{array}{l}\text { Mordan } \\
\text { maddeleri }\end{array}$} & \multicolumn{6}{|c|}{ Kök Boya } & \multicolumn{6}{|c|}{ Cehri } \\
\hline & \multicolumn{3}{|c|}{ İşlem görmemiş } & \multicolumn{3}{|c|}{ Art işlem görmüş } & \multicolumn{3}{|c|}{ İşlem görmemiş } & \multicolumn{3}{|c|}{ Art işlem görmüş } \\
\hline & $\mathrm{L}$ & a & $\mathrm{b}$ & $\mathrm{L}$ & a & $\mathrm{b}$ & $\mathrm{L}$ & a & $b$ & $\mathrm{~L}$ & a & $\mathrm{b}$ \\
\hline $\mathrm{CuSO}_{4} \cdot 5 \mathrm{H}_{2} \mathrm{O}$ & 18,2 & 14,33 & 5,52 & 25,38 & 18,94 & 15,91 & 31,17 & 13,53 & 25,48 & 22,95 & 13,9 & 16,96 \\
\hline $\mathrm{FeSO}_{4} \cdot 7 \mathrm{H}_{2} \mathrm{O}$ & 15,31 & 4,54 & 1,96 & 18,46 & 8,5 & 4,83 & 19,74 & 4,13 & 10,01 & 18,01 & 5,43 & 6,19 \\
\hline $\mathrm{KAl}\left(\mathrm{SO}_{4}\right)_{2} \cdot 12 \mathrm{H}_{2} \mathrm{O}$ & 33,71 & 37,25 & 30,82 & 23,79 & 21,91 & 17,05 & 45,6 & 17,93 & 53,51 & 31,95 & 17,89 & 23,65 \\
\hline $\mathrm{K}_{2} \mathrm{Cr}_{2} \mathrm{O}_{7}$ & 17,07 & 18,16 & 8,2 & 17,57 & 14,2 & 6,57 & 32,65 & 23,89 & 31,57 & 21,34 & 18,65 & 14,48 \\
\hline $\mathrm{K}_{2} \mathrm{CrO}_{4}$ & 19,13 & 19,57 & 8,05 & 18,66 & 13,91 & 6,07 & 27,94 & 23,24 & 26,77 & 23,06 & 20,01 & 17,6 \\
\hline $\mathrm{C}_{4} \mathrm{H}_{6} \mathrm{O}_{6}$ & 23,2 & 24,33 & 15,51 & 19,91 & 16,13 & 15,88 & 44,1 & 7,47 & 34,96 & 28,45 & 13,65 & 17,72 \\
\hline
\end{tabular}

Dweck, Anthony (2003), Natural Ingredients for Colouring and Styling, T Klin J, Cosmetol, UK.

Goverdina, C. H. Derksen vd. (2004), "Two Validated HPLC Methods for the Quantification of Alizarin and other Antraquiones in Rubia Tinctorum Cultivars, Phytochemical Analysis, 406.

Ingamells, Wilfred (1993), Colour for Textiles a User's Hand6ook, $S D C$, Bradford, UK.

Karadağ, Recep (2007), Doğal Boyamacıllk, T.C. Kültür ve Turizm Bakanlığı, Ankara.

Manojlovic, Nedeljko T. (2005), "Antifungal activity of Rubia tinctorum, Rhamnuz frangula nad Caloplaca cerina”, Fitoterapia, 76, s. 244-246.

Nizamlığlu, Mustafa Nizam, Nas Sebahattin, (2010), "Meyve ve Sebzelerde Bulunan Fenolik Bileşikler; Yapıları ve Önemleri", 5(1), s. 20-35.

Önal Adem (1995a), "Extraction of Dyestuff from Onion and its application in the dyeing of wool, feathereleather and cotton", J. Chemistry.

Önal Adem (1995b)," Extraction of Dyestuff from madder Plant and Dyeing of Wool, Feathered-leather and cotton", J. Chemistry.
Öztürk İsmail (1999), Doğal Bitkisel Boyalarla Yün Boyama, Dokuz Eylül Yayınları, İzmir.

Ranjana, Bhuyan vd. (2005), "Saikia, Isolation of colour Components from Native Dye-bearing Plants in Northeastern India", Bioresource Tech. 96 363-372.

TS EN 20105-C03, Tekstil-Renk Haslığı Deneyleri-Bölün C03: Yıkamaya Karşı Renk Haslığı Tayini-Deney 3, Türk Standartları, Nisan 1999.

TS 1008 EN ISO 105-B02, Yapay ışığa karşı Renk Haslığı Tayini, Türk Standartları, Ksenon ark soldurma lambasi deneyi.

TS 423-2-EN 20105 A02, Tekstil-Renk Haslığı Tayin Metotları - Bölüm A02: Solmanın Değerlendirilmesinde Gri skalanın Kullanılması.

TS 423-3-EN 20105 A03, Tekstil-Renk Haslığı Tayin MetotlarıBölüm A03: Renk Akmasının Değerlendirilmesinde Gri skalanın Kullanılması.

Anonim (1991), Bitkilerden Elde Edilen Boyalarla Yün Liflerinin Boyanması, Sanayi ve tic. Bakanlığı, Ankara. 